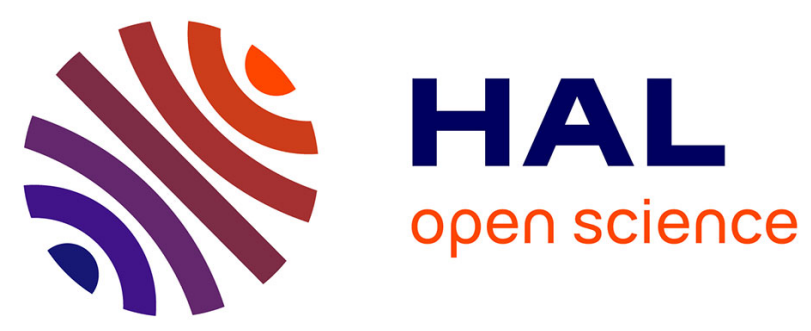

\title{
Probabilistic analysis of circular tunnels in homogeneous soil using response surface Methodology
}

\author{
Guilhem Mollon, Daniel Dias, Abdul-Hamid Soubra
}

\section{To cite this version:}

Guilhem Mollon, Daniel Dias, Abdul-Hamid Soubra. Probabilistic analysis of circular tunnels in homogeneous soil using response surface Methodology. Journal of Geotechnical and Geoenvironmental Engineering, 2009, 135 (9), pp.1314-1325. 10.1061/(ASCE)GT.1943-5606.0000060 . hal-01007210

\section{HAL Id: hal-01007210 https://hal.science/hal-01007210}

Submitted on 29 Oct 2018

HAL is a multi-disciplinary open access archive for the deposit and dissemination of scientific research documents, whether they are published or not. The documents may come from teaching and research institutions in France or abroad, or from public or private research centers.
L'archive ouverte pluridisciplinaire HAL, est destinée au dépôt et à la diffusion de documents scientifiques de niveau recherche, publiés ou non, émanant des établissements d'enseignement et de recherche français ou étrangers, des laboratoires publics ou privés. 


\title{
Probabilistic Analysis of Circular Tunnels in Homogeneous Soil Using Response Surface Methodology
}

\author{
Guilhem Mollon ${ }^{1}$; Daniel Dias²; and Abdul-Hamid Soubra ${ }^{3}$
}

\begin{abstract}
A probabilistic analysis of a shallow circular tunnel driven by a pressurized shield in a frictional and/or cohesive soil is presented. Both the ultimate limit state (ULS) and serviceability limit state (SLS) are considered in the analysis. Two deterministic models based on numerical simulations are used. The first one computes the tunnel collapse pressure and the second one calculates the maximal settlement due to the applied face pressure. The response surface methodology is utilized for the assessment of the Hasofer-Lind reliability index for both limit states. Only the soil shear strength parameters are considered as random variables while studying the ULS. However, for the SLS, both the shear strength parameters and Young's modulus of the soil are considered as random variables. For ULS, the assumption of uncorrelated variables was found conservative in comparison to the one of negatively correlated parameters. For both ULS and SLS, the assumption of nonnormal distribution for the random variables has almost no effect on the reliability index for the practical range of values of the applied pressure. Finally, it was found that the system reliability depends on both limit states. Notice however that the contribution of ULS to the system reliability was not significant. Thus, SLS can be used alone for the assessment of the tunnel reliability.
\end{abstract}

Keywords: Shields, tunneling; Settlement; Serviceability; Ultimate loads; Limit states; System reliability.

\section{Introduction}

The stability analysis of tunnels and the computation of soil displacements due to tunneling were commonly performed using deterministic approaches (e.g., Jardine et al. 1986; Dias et al. 1997; Potts and Addenbrooke 1997; Dias et al. 2002; Yoo 2002; Jenck and Dias 2003; Mroueh and Shahrour 2003; Ribeiro e Sousa et al. 2003; Jenck and Dias 2004; Dias and Kastner 2005; Wong et al. 2006; Eclaircy-Caudron et al. 2007). A reliabilitybased approach for the analysis of tunnels is more rational since it enables one to consider the inherent uncertainty of the input parameters. In this paper, a reliability-based analysis of a shallow circular tunnel driven by a pressurized shield in a $c-\varphi$ soil is presented. Both the ultimate limit state (ULS) and the serviceability limit state (SLS) are considered in the analysis. Two deterministic models based on the Lagrangian explicit finite-difference code FLAC $^{3 \mathrm{D}}$ (1993) are used. The first one involves the tunnel face stability in the ULS and focuses on the computation of the tunnel collapse pressure. The second one emphasizes the SLS and

${ }^{1} \mathrm{Ph} . \mathrm{D}$. Student, INSA Lyon, LGCIE Site Coulomb 3, Géotechnique, Bât. J.C.A. Coulomb, Domaine Scientifique de la Doua, 69621 Villeurbanne Cedex, France. E-mail: Guilhem.Mollon@insa-lyon.fr

${ }^{2}$ Associate Professor, INSA Lyon, LGCIE Site Coulomb 3, Géotechnique, Bât. J.C.A. Coulomb, Domaine Scientifique de la Doua, 69621 Villeurbanne Cedex, France. E-mail: Daniel.Dias@insa-lyon.fr

${ }^{3}$ Professor, Institut de Recherche en Génie Civil et Mécanique, Univ. of Nantes, UMR CNRS 6183, Bd. de l'université, BP 152, 44603 SaintNazaire, France (corresponding author). E-mail: Abed.Soubra@univnantes.fr calculates the maximal settlement due to the applied face pressure. The response surface methodology (RSM) is utilized to find an approximation of the analytically unknown performance function and the corresponding reliability index for both limit states. The random variables considered in the analysis are the soil shear strength parameters $c$ and $\varphi$ for the ULS. However, for the SLS, both the shear strength parameters and Young's modulus of the soil are used. After a brief description of the two deterministic models, the basic concepts of the theory of reliability are presented. Then, the probabilistic analysis and the corresponding numerical results are presented and discussed.

\section{Deterministic Numerical Modeling of Tunnel Face Stability and Face Pressure-Induced Displacement Using FLAC ${ }^{3 D}$}

FLAC $^{3 \mathrm{D}}$ is a commercially available three-dimensional finitedifference code, in which an explicit Lagrangian calculation scheme and a mixed discretization zoning technique are used. This code includes an internal programing option (FISH), which enables the user to add his own subroutines. In this software, although a static (i.e., nondynamic) mechanical analysis is required, the equations of motion are used. The solution to a static problem is obtained through the damping of a dynamic process by including damping terms that gradually remove the kinetic energy from the system. A key parameter used in the software is the so-called "unbalanced force ratio." It is defined at each calculation step (or cycle) as the average unbalanced mechanical force for all the grid points in the system divided by the average applied mechanical force for all these grid points. The system may be stable (called also in a steady state of static equilibrium) or unstable (called also in a steady state of plastic flow). A steady state of static equilibrium is one for which a state of static equilibrium is achieved in the soil-structure system due to given service loads 


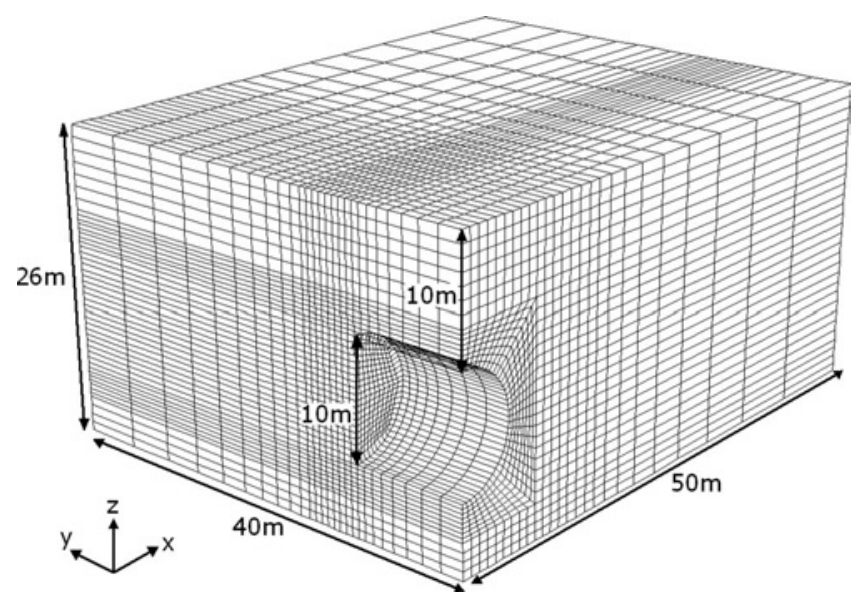

Fig. 1. Soil domain and mesh used in $\operatorname{FLAC}^{3 \mathrm{D}}$ for ULS

and for which the unbalanced force ratio decreases with the number of cycles increase and then it becomes less than a prescribed tolerance (e.g., $10^{-5}$ as suggested in FLAC ${ }^{3 \mathrm{D}}$ software). On the other hand, a steady state of plastic flow is one in which soil failure is achieved. In this case, the unbalanced force ratio decreases with the number of cycles increase and then attains a quasi-constant nonvarying value. This value is higher than the one corresponding to the steady state of static equilibrium.

\section{Numerical Simulations}

This section focuses on (1) the face stability analysis at ULS and (2) the assessment of face pressure-induced soil displacements at SLS, in the case of a circular tunnel driven by a pressurized shield. A uniform retaining pressure is applied to the tunnel face to simulate tunneling under compressed air. Although a random soil is studied in this paper, the deterministic FLAC ${ }^{3 \mathrm{D}}$ simulations consider a homogeneous soil. The randomness of the soil is taken into account from one simulation to another. Because of symmetry, only one-half of the entire domain is considered in the analysis, as shown in Fig. 1 (the velocity field being symmetrical with respect to the vertical plane passing through the longitudinal axis of the tunnel). A nonsymmetrical velocity field would be necessary only for the computation of the reliability of a tunnel in a spatially variable soil (i.e., where the random parameters are considered as random processes). In all subsequent calculations of the ULS and SLS, the following procedure is performed before any simulation: geostatic stresses are first applied to the soil, then several cycles are run in order to arrive at a steady state of static equilibrium, and finally, the obtained displacements are set to zero in order to obtain the soil displacements due only to the pressure applied on the tunnel face.

\section{ULS: Face Stability Analysis}

Although the present section is intended to the evaluation of the tunnel face stability, no safety factor is calculated. Indeed, only the highest pressure applied to the tunnel face for which soil collapse would occur is computed. This collapse pressure is the one for which the soil in front of the tunnel face undergoes downward movement. It is called the tunnel active pressure.

A circular tunnel of diameter $D=10 \mathrm{~m}$ and cover $C=10 \mathrm{~m}$ (i.e., $C / D=1$ ) driven in a $c-\varphi$ soil is considered in this paper (cf.
Fig. 1). The size of the numerical model is $50 \mathrm{~m}$ in the $X$ direction, $26 \mathrm{~m}$ in the $Z$ direction, and $40 \mathrm{~m}$ in the $Y$ direction. These dimensions are chosen so as not to affect the value of the tunnel collapse pressure. A three-dimensional nonuniform mesh is used. The present model is composed of approximately 27,000 zones. The tunnel face region was subdivided into 198 zones since very high stress gradients were developed in that region.

For the displacement boundary conditions, the bottom boundary was assumed to be fixed and the vertical boundaries were constrained in motion in the normal direction.

A conventional elastic perfectly plastic model based on the Mohr-Coulomb failure criterion was adopted to represent the soil. The soil elastic properties employed are Young's modulus $E$ $=240 \mathrm{MPa}$ and Poisson's ratio $\nu=0.3$. The values of the angle of internal friction and cohesion of the soil used in the analysis are $\varphi=17^{\circ}$ and $c=7 \mathrm{kPa}$, respectively. The soil dilation angle $\psi$ was assumed equal to zero in accordance with the commonly used relationship $\psi=\varphi-30^{\circ}$. The soil unit weight was taken equal to $18 \mathrm{kN} / \mathrm{m}^{3}$. Notice that the soil elastic properties have a negligible effect on the collapse pressure. A concrete lining of $0.4-\mathrm{m}$ thickness is used in the analysis. The lining is simulated by a shell of linear elastic behavior. Its elastic properties are Young's modulus $E=15 \mathrm{GPa}$ and Poisson's ratio $\nu=0.2$. The lining is connected to the soil via interface elements that follow Coulomb's law. The interface is assumed to have a friction angle equal to two-thirds of the soil angle of internal friction (i.e., $11,3^{\circ}$ ) and cohesion equal to zero. Normal stiffness $K_{n}=10^{11} \mathrm{~Pa} / \mathrm{m}$ and shear stiffness $K_{n}$ $=10^{11} \mathrm{~Pa} / \mathrm{m}$ were assigned to this interface. These parameters are a function of the neighboring elements rigidity (FLAC ${ }^{3 \mathrm{D}}$ 1993) and do not have a major influence on the collapse pressure.

For the computation of a tunnel collapse pressure using FLAC $^{3 \mathrm{D}}$, a stress control method is adopted in this paper. Notice that a displacement control method could be used instead since it requires much less computation time. However, this approach requires a priori assumption concerning the distribution of the displacement on the tunnel face (e.g., uniform or parabolic distribution, etc.) and may lead to erroneous results. The next section is devoted to the presentation of the stress control method used for the computation of the tunnel collapse pressure.

\section{Stress Control Method}

Two methods may be used for the computation of the tunnel collapse pressure. The first one is the simple bisection approach and the second one is called the improved bisection method. In the simple bisection approach, simulations are run for a series of trial values of the tunnel pressure $\sigma^{\text {trial }}$. The value of $\sigma^{\text {trial }}$ at which failure occurs is found using bracketing and bisection approaches as follows:

1. Upper and lower brackets are first established.

- The initial lower bracket corresponds to any trial pressure for which the system is unstable. This state corresponds to a nonnull face extrusion velocity at each point of the tunnel face [see, for instance, the horizontal velocity of Point A shown in Fig. 2(b) where Point $A$ is located at the centre of the tunnel face]. This nonnull velocity at Point A corresponds to a continuously increasing horizontal displacement at this point, as shown in Fig. 2(a), and it means that a steady state of failure or plastic flow is achieved in this case.

- The initial upper bracket corresponds to any trial pressure in which the system is stable. This state corresponds to a zero face extrusion velocity at each point of the tunnel face [see, for instance, the horizontal velocity of Point A shown in Fig. 2(b)]. This zero velocity at Point A corresponds to a constant 

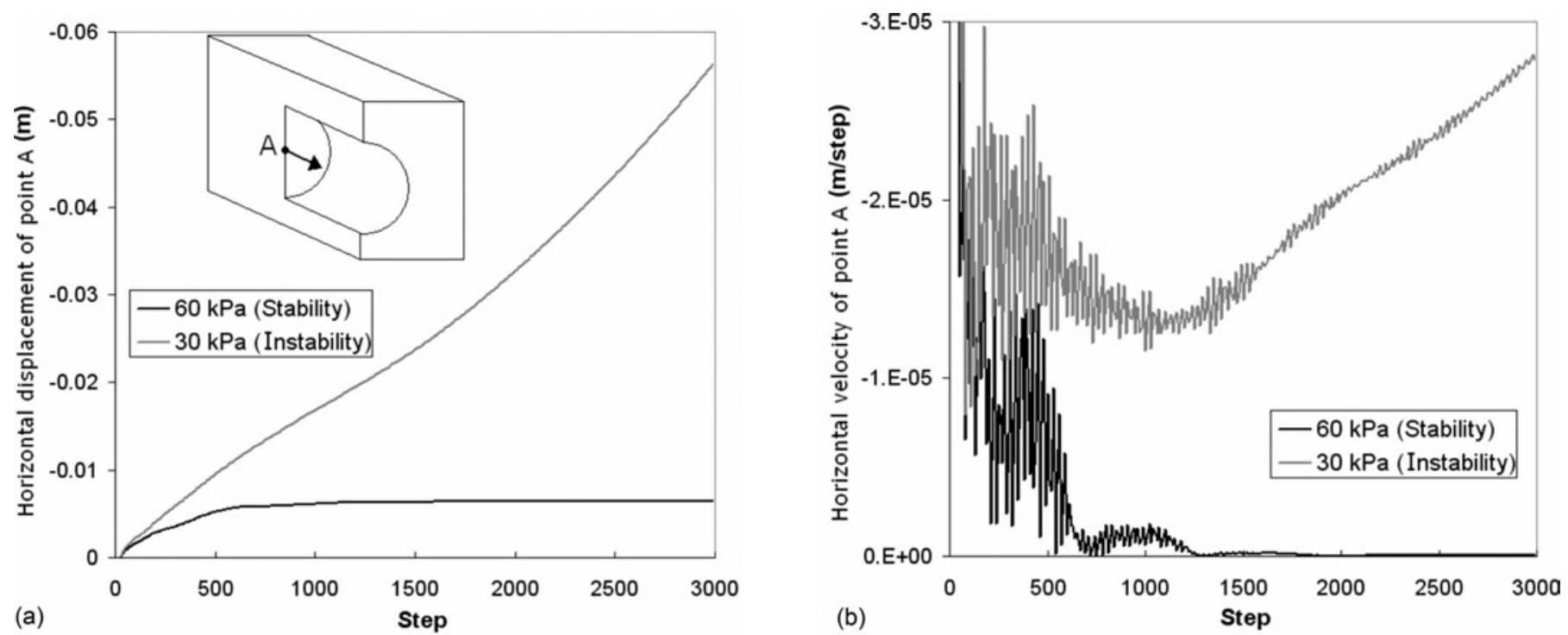

Fig. 2. (a) Horizontal displacement; (b) horizontal velocity of Point A (center of tunnel face) during stability (static equilibrium) and instability (plastic flow)

horizontal displacement at this point as long as the number of cycles increases, as shown in Fig. 2(a), and it means that a steady state of static equilibrium is achieved in this case.

2. Next, a new value, midway between the upper and lower brackets, is tested. If the system is stable for this midway value, the upper bracket is replaced by this new trial pressure. If the system does not reach equilibrium, the lower bracket is then replaced by the midway value.

3. Steps 1 and 2 are repeated until the difference between upper and lower brackets is less than a specific tolerance.

The simple bisection method consists of running several cycles for the two states of plastic flow and static equilibrium corresponding, respectively, to the lower and upper brackets. This procedure is very time consuming because the plastic flow state usually occurs after a large number of cycles. This can be dramatic if one is looking for a precise value of the collapse pressure. A more efficient method called in this paper as "the improved bisection approach" may be used. It allows one to check if the system is unstable much more quickly than the classical approach. This method is similar to that used in FLAC ${ }^{3 \mathrm{D}}$ software for the determination of the safety factor. It may be briefly described as follows. First, a very high value of the cohesion is affected to the soil. This makes the soil behave as an elastic material. Second, the whole system is set to an unbalanced state by doubling artificially all the values of the internal stresses. The method consists of determining a "representative" number $N$ of cycles. It corresponds to the number of computation cycles that the software must run to return to a static equilibrium state from the previous unbalanced state. This number is generally close to 3,000 steps. When $N$ is determined, the initial value of the cohesion is restored. The system is considered in a steady state of plastic flow if it remains unstable after performing these $N$ cycles. As one can easily see, there is no need to run a large number of cycles to check the instability of the system in the improved bisection method. Interested readers by this method may refer for more details to Fast Lagrangian Analysis of Continua (FLAC ${ }^{3 \mathrm{D}}$ ) (1993). The improved bisection method was coded in FISH language into the FLAC ${ }^{3 \mathrm{D}}$ software. It allows one to obtain the collapse pressure more quickly than the classical bisection approach.
The CPU time is variable but can be longer than 1 day when using the classical bisection method and becomes equal to $90 \mathrm{~min}$ (on a Core2 Quad CPU 2.40-GHz PC) when one uses the improved bisection method. Thus, the improved bisection technique is adopted for the computation of the tunnel collapse pressure. Bracketing and bisection are repeated until the difference between the upper and lower brackets becomes smaller than a prescribed tolerance (e.g., $100 \mathrm{~Pa}$ in this paper). The tunnel face collapse pressure was found equal to $\sigma_{c}=34.5 \mathrm{kPa}$. The corresponding collapse velocity field given by FLAC ${ }^{3 \mathrm{D}}$ is provided in Fig. 3. Stability against collapse is ensured as long as the applied pressure $\sigma_{t}$ is greater than the tunnel collapse pressure $\sigma_{c}$.

\section{SLS: Maximal Settlement}

First, it should be emphasized here that the deterministic numerical simulations used in the paper for the SLS are limited to the computation of the ground settlement due to only the applied face pressure. Notice however that the ground settlement is primarily due to the shield tail void. In real shield tunneling cases, the proportion of ground settlement induced by the face pressure may be less than $25 \%$ of the total settlement (cf. Vanoudheusden 2006). The settlement due to shield tunneling is pretty much affected by the closure of tail void, grouting, unlined length, soil

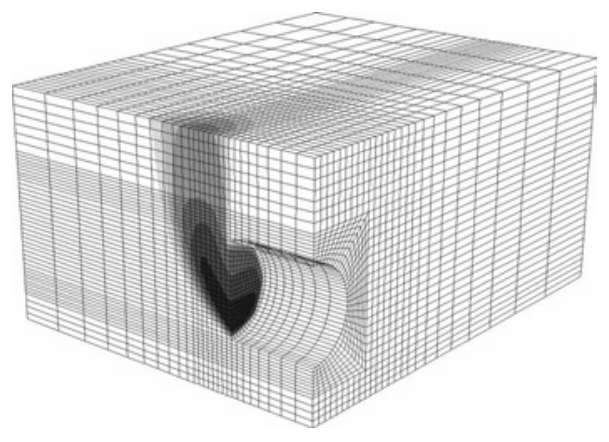

Fig. 3. Collapse velocity field $\left(\sigma_{c}=34.5 \mathrm{kPa}\right)$ 




Fig. 4. Soil domain and mesh used in $\operatorname{FLAC}^{3 \mathrm{D}}$ for SLS

loss, etc., during tunneling. Thus, the present numerical simulations can only be regarded as an idealized condition ignoring many important factors concerning tunneling construction. The writers consider the ground settlement due to the sole effect of the face pressure for the following reasons. The face pressure is the parameter that has the most influence on stability. On the other hand, several parameters (among them the face pressure) would influence the ground settlement. In this paper, the effect of only one tunneling parameter (i.e., the face pressure) on both the stability and deformation analyses of the pressurized shield tunneling was considered in order to be able to make a comparison of the tunnel reliability on both the SLS and ULS due to this unique parameter.

For the computation of the maximal settlement due to an applied pressure $\sigma_{t}$ on the tunnel face, the excavation by the shield is also modeled here by the stress control method in order to take into account the excavation steps. Contrary to the ULS where the excavation steps were not necessary in the computation procedure of the collapse pressure, in the present SLS, a total of 50 excavation steps (with a length of $1 \mathrm{~m}$ for each step) were performed. Cycling was performed after each excavation step in order to obtain the corresponding displacement. It should be mentioned here that the excavation and the concrete lining installation were applied concurrently. This leads, as mentioned before, to a significant simplification concerning the simulation of tunneling construction and provides the settlement induced by only the face decompression.

An elastic perfectly plastic model is still used here for the soil since it enables the development of plastic zones that may occur near the tunnel face for the entire range of variation in the applied pressure $\sigma_{t}$ and it leads to more accurate solutions than a purely elastic model. A more sophisticated model including nonlinearity in the elastic range would be of interest and may give better results for the settlement. However, it is out of the scope of this paper and will be used in a future research. The numerical simulations have shown that the longitudinal limits of the model have a significant influence on the value of the maximal settlement. This is the reason why the mesh used for the assessment of the maximal settlement is much more extended than the previous one along the $Y$ axis. Notice however that the same geometry is adopted here in the $X-Z$ section. The mesh used is presented in Fig. 4. Fig. 5(a) shows the settlement along the $Y$ axis after 50 steps of excavation for an applied pressure of $40 \mathrm{kPa}$. This curve clearly shows the zone, which is significantly influenced by the boundary $Y=0$ of the model. The maximal settlement $(4.7 \mathrm{~mm}$ in this case) occurs about $10 \mathrm{~m}$ behind the tunnel face. Fig. 5(b) presents the maximal settlement versus the number of excavation

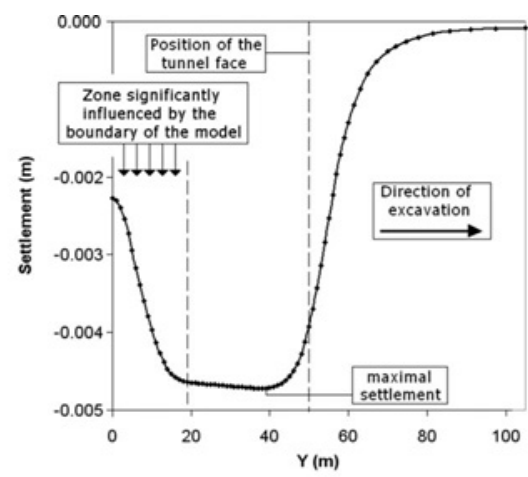

(a)

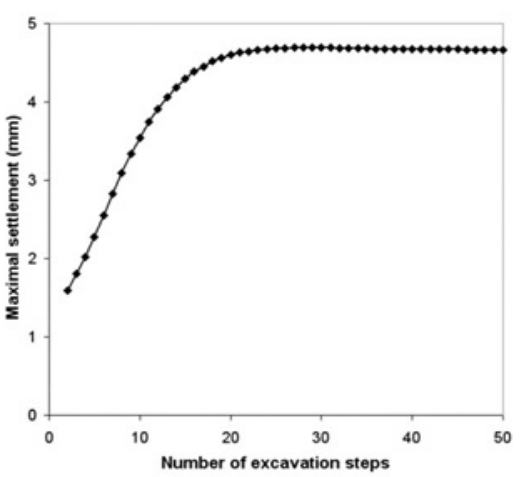

Fig. 5. Settlement determination in SLS: (a) settlement along $Y$ axis after 50 excavation steps when $\sigma_{t}=40 \mathrm{kPa}$; (b) maximal settlement versus number of excavation steps

steps. This figure shows the stabilization of the maximal settlement after about 30 steps of $1 \mathrm{~m}$ long. Thus, one can conclude that the 50 steps of excavation adopted in this paper are sufficient to give accurate result for the maximal settlement. Finally, notice that the CPU time required for each computation of the maximal settlement was found to be $130 \mathrm{~min}$ on a Core2 Quad CPU 2.40$\mathrm{GHz} \mathrm{PC}$.

\section{Ellipsoid Approach in Reliability Theory}

The reliability index of a geotechnical structure is a measure of the safety that takes into account the inherent uncertainties of the input parameters. A widely used reliability index is the Hasofer and Lind (1974) index. Its matrix formulation is (Ditlevsen 1981)

$$
\beta_{\mathrm{HL}}=\min _{x \in F} \sqrt{\left(x-\mu_{x}\right)^{T} C^{-1}\left(x-\mu_{x}\right)}
$$

in which $x=$ vector representing the $n$ random variables; $\mu_{x}$ =vector of their mean values; and $C=$ their covariance matrix. The minimization of Eq. (1) is performed subject to the constraint $G(x) \leq 0$, where the limit state surface $G(x)=0$ separates the $n$-dimensional domain of random variables into two regions: a failure region $F$ represented by $G(x) \leq 0$ and a safe region given by $G(x)>0$.

Low and Tang (1997a, 2004) introduced the concept of an expanding ellipsoid (or ellipse in the two-dimensional case), as shown in Fig. 6, and led to a simple method of computing the Hasofer-Lind reliability index in the physical space of the random variables. These writers reported that the Hasofer-Lind reliability index $\beta_{\mathrm{HL}}$ may be regarded as the codirectional axis ratio of the smallest ellipsoid that just touches the limit state surface to the 


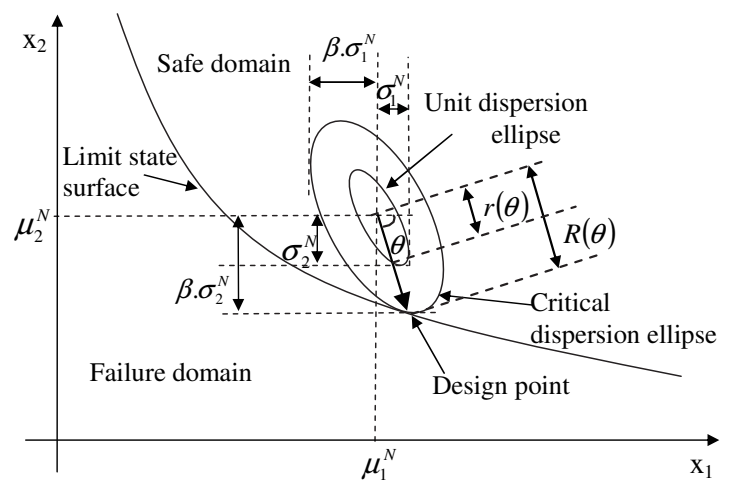

Fig. 6. Design point and equivalent normal dispersion ellipses in the space of two random variables

unit dispersion ellipsoid [i.e., corresponding to $\beta_{\mathrm{HL}}=1$ in Eq. (1) without the min]. They also stated that finding the smallest ellipsoid that is tangent to the limit state surface is equivalent to finding the most probable failure point. When the random variables are nonnormal and correlated, the optimization approach uses the Rackwitz-Fiessler equations to compute the equivalent normal mean $\mu_{x}^{N}$ and the equivalent normal standard deviation $\sigma_{x}^{N}$ without the need to diagonalize the correlation matrix, as shown in Low and Tang (2004), Low (2005), and Youssef Abdel Massih et al. (2008). Furthermore, the iterative computations of the equivalent normal mean $\mu_{x}^{N}$ and the equivalent normal standard deviation $\sigma_{x}^{N}$ for each trial design point are automatic during the constrained optimization search.

In this paper, by the method of Low and Tang, one literally sets up a tilted ellipsoid in Microsoft Excel and uses the solver to minimize the dispersion ellipsoid subject to the constraint that it is tangent to the limit state surface. Eq. (1) may be rewritten as (Low and Tang 1997b, 2004)

$$
\beta_{\mathrm{HL}}=\min _{x \in F} \sqrt{\left[\frac{x-\mu_{x}^{N}}{\sigma_{x}^{N}}\right]^{T}[R]^{-1}\left[\frac{x-\mu_{x}^{N}}{\sigma_{x}^{N}}\right]}
$$

in which $[R]^{-1}=$ inverse of the correlation matrix. This equation will be used to set up the ellipsoid in Microsoft Excel since the correlation matrix $[R]$ displays the correlation structure more explicitly than the covariance matrix $[C]$.

From the first order reliability method (FORM) and the Hasofer-Lind reliability index $\beta_{\mathrm{HL}}$, one can approximate the failure probability as follows:

$$
P_{f} \approx \Phi\left(-\beta_{\mathrm{HL}}\right)
$$

where $\Phi(\cdot)$ = cumulative distribution function of a standard normal variable. In this method, the limit state function is approximated by a hyperplane tangent to the limit state surface at the design point.

\section{Reliability Analysis of Circular Tunnels}

The aim of this paper is to perform a reliability analysis of a circular tunnel driven by a pressurized shield in a $c-\varphi$ soil. Two failure or unsatisfactory performance modes are considered in the analysis. The first one involves the ULS and emphasizes on the computation of the tunnel collapse pressure. The second one considers the SLS and focuses on the maximal settlement due to the applied face pressure. The two deterministic models presented
Table 1. Fifteen Simulations Considered for the Parametric Study of the Settlement (for Each Simulation, One Parameter May Take Three Different Values Including Its Reference Value While the Four Other Parameters Are Fixed to their Reference Values, i.e., a Total of $5 \times 3=15$ Simulations)

\begin{tabular}{lccccc}
\hline Variable & $\begin{array}{c}E \\
(\mathrm{MPa})\end{array}$ & $v$ & $\begin{array}{c}c \\
(\mathrm{kPa})\end{array}$ & $\begin{array}{c}\varphi \\
(\text { degrees })\end{array}$ & $\begin{array}{c}\psi \\
(\text { degrees })\end{array}$ \\
\hline $\begin{array}{l}\text { Reference } \\
\text { values }\end{array}$ & 240 & 0.3 & 7 & 17 & 0 \\
$\begin{array}{l}\text { Case 1 } \\
\text { Case 2 }\end{array}$ & $\begin{array}{c}400 \\
\text { Reference } \\
\text { value of } E\end{array}$ & $\begin{array}{c}\text { Reference } \\
\text { value of } v\end{array}$ & $\begin{array}{c}\text { Reference } \\
\text { value of } c\end{array}$ & $\begin{array}{c}\text { Reference } \\
\text { value of } \varphi\end{array}$ & 5 \\
Case 3 & 100 & 0.15 & 0 & 12 & $\begin{array}{c}\text { Reference } \\
\text { value of } \psi\end{array}$ \\
\hline
\end{tabular}

above are used. The RSM is employed to find an approximation of the analytically unknown performance functions. Due to the relatively low effect of the elastic modulus $E$ and the Poisson ratio $\nu$ on the tunnel collapse pressure, only $c$ and $\varphi$ will be considered as random variables while studying the ULS; the soil dilation angle is taken equal to zero in the present analysis and it is considered as a deterministic parameter. For the study of the SLS, a parametric study is performed here to check the sensitivity of the maximal settlement to the five parameters of the elastoplastic Mohr-Coulomb constitutive model (i.e., $E, v, c, \varphi$, and $\psi$ ). A total of 15 simulations corresponding to three different values of each parameter (see Table 1) are studied, as shown in Fig. 7. This study clearly shows that Poisson coefficient $v$ and dilatancy angle $\psi$ have almost no effect on the maximal settlement, whereas $E, c$, and $\varphi$ have a significant effect on this settlement. Furthermore, it was shown that small values of $c$ and $\varphi$ may lead to instability (plastic flow) of the tunnel face. Consequently, only the randomness of $c, \varphi$, and $E$ will be taken into consideration in the analysis of the SLS.

For the statistical moments of the random variables, Phoon and Kulhawy (1999) stated from an exhaustive study of cone penetration test and triaxial tests results that the coefficient of variation $(\mathrm{COV})$ of the cohesion could vary from 10 to $55 \%$; Cherubini et al. (1993) recommended the interval $12-45 \%$ for the stiff clays and a higher limit of $80 \%$ for very soft clays. For the COV of the friction angle, Phoon and Kulhawy (1999) proposed

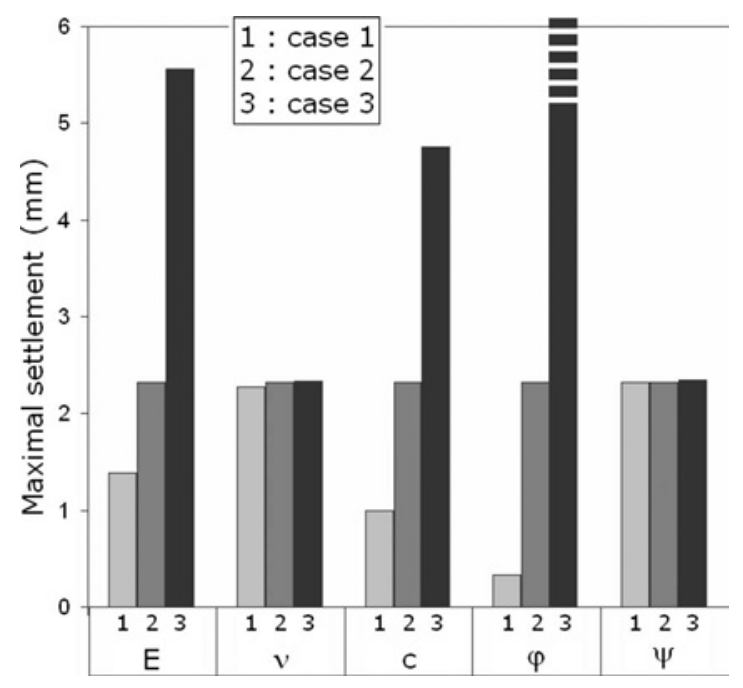

Fig. 7. Parametric study for the maximal settlement 
the interval of $5-15 \%$. For the COV of Young's modulus, the same authors proposed 30\%, Bauer and Pula (2000) suggested $15 \%$, and Baecher and Christian (2003) proposed the interval $2-42 \%$. The illustrative values used in this paper for the statistical moments of the shear strength parameters and Young's modulus belong to the intervals proposed by the above cited authors and are given as follows: $\mu_{c}=7 \mathrm{kPa}, \mu_{\varphi}=17^{\circ}, \mu_{E}=240 \mathrm{MPa}$, $\mathrm{COV}_{c}=20 \%, \mathrm{COV}_{\varphi}=10 \%$, and $\mathrm{COV}_{E}=15 \%$. For the probability distribution of the random variables, two cases may be studied. In the first case, referred to as normal variables, $c, \varphi$, and $E$ are considered as normal variables. In the second case, referred to as nonnormal variables, $c$ and $E$ are assumed to be lognormally distributed while $\varphi$ is assumed to be bounded and a beta distribution is used (Fenton and Griffiths 2003). The parameters of the beta distribution are determined from the mean value and standard deviation of $\varphi$ (Haldar and Mahadevan 2000). It should be mentioned that for the ULS for which only the shear strength parameters are considered as random variables, $E$ will be considered as deterministic with its mean value and with a zero COV. Concerning the coefficients of correlation between random variables, only a negative correlation between $c$ and $\varphi$ with $\left(\rho_{c, \varphi}=-0.5\right)$ is assumed to exist when these random variables are considered as correlated.

After a brief description of the performance functions used in the present analysis, the RSM and its numerical implementation are presented. Then, the probabilistic numerical results based on this method are presented and discussed.

\section{Performance Functions}

Two performance functions are used in the reliability analysis. The first one is defined with respect to the collapse mode of failure in the ULS as follows:

$$
G_{1}=\frac{\sigma_{t}}{\sigma_{c}}-1
$$

where $\sigma_{t}=$ applied pressure on the tunnel face and $\sigma_{c}=$ tunnel collapse pressure computed using FLAC $^{3 \mathrm{D}}$. The second performance function, which is defined in the SLS with respect to a prescribed admissible settlement, is given as follows:

$$
G_{2}=v_{\max }-v
$$

where $\nu=$ maximal settlement (as explained before) calculated by FLAC $^{3 \mathrm{D}}$ due to an applied pressure $\sigma_{t}$ and $\nu_{\max }=$ maximal admissible prescribed settlement.

\section{Response Surface Method}

When using numerical simulations, the closed form solution of the performance function is not available. Thus, the determination of the reliability index is not straightforward. An algorithm based on the RSM proposed by Tandjiria et al. (2000) is used in this paper with the aim to calculate the reliability index and the corresponding design point. The basic idea of this method is to approximate the performance function by an explicit function of the random variables and to improve the approximation via iterations. The approximate performance function widely used in literature has a quadratic form. It uses a second order polynomial with squared terms. The expression of this approximation is given by

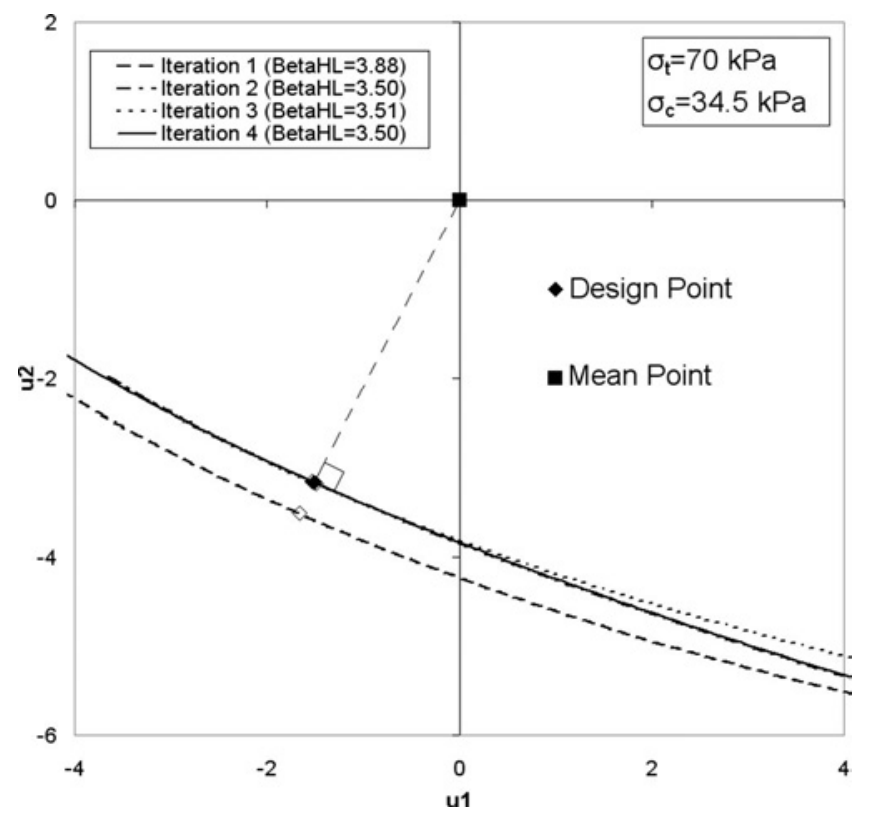

Fig. 8. Evolution of the tentative response surface in the $\left(u_{1}, u_{2}\right)$ space

$$
G(x)=a_{0}+\sum_{i=1}^{n} a_{i} x_{i}+\sum_{i=1}^{n} b_{i} x_{i}^{2}
$$

where $x_{i}=$ random variables; $n=$ number of the random variables; and $\left(a_{i}, b_{i}\right)=$ coefficients to be determined. In this paper, two random variables $c$ and $\varphi$ are considered for the ULS (i.e., $n=2$ ). However, $n=3$ for the SLS since the random variables used in that case are $c, \varphi$, and $E$. For both limit states, the random variables are characterized by their mean values $\mu_{i}$ and their COVs $\sigma_{i}$. A brief explanation of the algorithm used is as follows:

1. Evaluate the performance function $G(x)$ at the mean value point $\mu$ and the $2 n$ points each at $\mu \pm k \sigma$, where $k$ is usually equal to 1 (this parameter may be varied in some cases if necessary).

2. The above $2 n+1$ values of $G(x)$ can be used to solve Eq. (6) for the coefficients $\left(a_{i}, b_{i}\right)$. This obtains a tentative response surface function.

3. Solve Eq. (1) to obtain a tentative design point and a tentative $\beta_{\mathrm{HL}}$ subject to the constraint that the tentative response surface function of Step 2 be equal to zero.

4. Repeat Steps 1-3 until convergence. Each time Step 1 is repeated, the $2 n+1$ sampled points are centered at the new tentative design point of Step 3.

Notice finally that Steps 2 and 3 were done using the optimization tools in Microsoft Excel. However, Step 1 was performed using deterministic FLAC $^{3 \mathrm{D}}$ calculations.

\section{Numerical Results}

\section{ULS}

It should be mentioned here that the quadratic approximation given by Eq. (6) was used for the computation of the reliability index in the ULS. Fig. 8 shows the evolution of the successive tentative response surfaces in the standard space $\left(u_{1}, u_{2}\right)$ for an applied pressure equal to $70 \mathrm{kPa}$ when the random variables are 


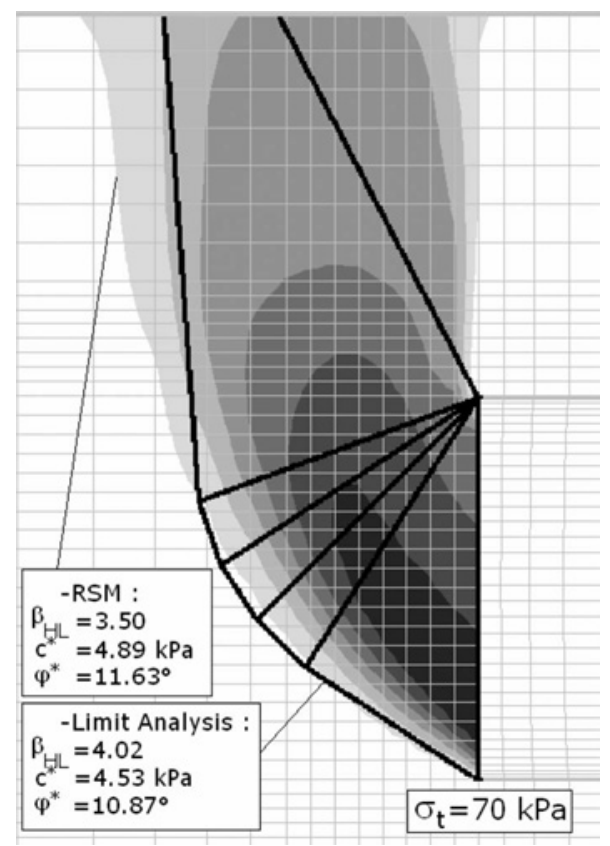

Fig. 9. Comparison of the reliability results and the corresponding failure pattern as given by the present RSM and the limit analysis model by Mollon et al. (2009)

assumed normal and uncorrelated. A convergence criterion on the reliability index was adopted. It considers that convergence is reached when a difference (in absolute value) smaller than $10^{-2}$ between two successive reliability indexes is achieved. One can notice that this criterion is reached after three to five iterations. Thus, only $15-25$ numerical simulations by FLAC ${ }^{3 \mathrm{D}}$ were necessary. The corresponding $\mathrm{CPU}$ time required is about 20 $\times 90 \mathrm{~min}=1,800 \mathrm{~min}$ (i.e., $30 \mathrm{~h}$ ). A value of 3.50 was found for the reliability index in the case of uncorrelated $\left(\rho_{c, \varphi}=0\right)$ variables and a value of 4.47 for correlated $\left(\rho_{c, \varphi}=-0.5\right)$ variables. These values correspond to failure probabilities of $2.3 \times 10^{-4}$ and 4.0 $\times 10^{-6}$ as calculated by FORM approximation.

Fig. 9 shows a comparison between the reliability results (re- liability index, design point, and failure pattern) as given by the present model using RSM and the limit analysis model by Mollon et al. (2009) in the case of uncorrelated normal variables. Although FLAC ${ }^{3 \mathrm{D}}$ and limit analysis give quite close results concerning the collapse pressure, the limit analysis model by Mollon et al. (2009) suffers from the fact that only one part of the circular tunnel face (i.e., an inscribed ellipse) is involved by failure, the remaining part of this area is at rest. Hence, the aim of using a FLAC $^{3 \mathrm{D}}$ model is that this model is a more rigorous deterministic one in which no a priori assumptions are made concerning the shape of the failure mechanism. Notice finally that the collapse pressure at the design point as computed by $\mathrm{FLAC}^{3 \mathrm{D}}$ is equal to $70.07 \mathrm{kPa}$. This pressure is to be compared to the target pressure of $70 \mathrm{kPa}$. Thus, one can consider the RSM algorithm used in this paper as sufficiently accurate for the computation of the reliability index.

\section{Reliability Index and Design Point}

Table 2 presents the Hasofer-Lind reliability index and the corresponding design point for different values of the applied pressure $\sigma_{t}$. The cases of normal, nonnormal, correlated $\left(\rho_{c, \varphi}=-0.5\right)$, and uncorrelated $\left(\rho_{c, \varphi}=0\right)$ shear strength parameters are considered.

The plot of the reliability index versus the applied pressure $\sigma_{t}$ is given in Fig. 10. The reliability index decreases with the decrease in the applied pressure until it vanishes for an applied pressure equal to the deterministic collapse pressure. This case corresponds to a deterministic state of failure for which $\sigma_{t}=\sigma_{c}$ using the mean values of the random variables for normal variables (or the equivalent normal mean values for nonnormal variables) and the failure probability is equal to $50 \%$. The comparison of the results of correlated variables with those of uncorrelated variables shows that the reliability index corresponding to uncorrelated variables is smaller than the one of negatively correlated variables. One can conclude that the hypothesis of uncorrelated shear strength parameters is conservative in comparison to the one of negatively correlated parameters. For instance, when the applied pressure is equal to $60 \mathrm{kPa}$, the reliability index increases by $30 \%$ if the variables $c$ and $\varphi$ are considered as negatively correlated. The increase in the reliability index due to a negative

Table 2. Reliability Index and Design Point for ULS for Normal, Nonnormal, Uncorrelated, and Correlated Shear Strength Parameters

\begin{tabular}{|c|c|c|c|c|c|c|c|c|c|c|}
\hline \multirow[b]{2}{*}{$\begin{array}{l}\sigma_{t} \\
(\mathrm{kPa})\end{array}$} & \multicolumn{5}{|c|}{$\rho_{c, \varphi}=0.0$} & \multicolumn{5}{|c|}{$\rho_{c, \varphi}=-0.5$} \\
\hline & $\begin{array}{c}c^{*} \\
(\mathrm{kPa})\end{array}$ & $\varphi^{*}$ (degrees) & $\beta_{\mathrm{HL}}$ & $F_{c}$ & $F_{\varphi}$ & $\begin{array}{c}c^{*} \\
(\mathrm{kPa})\end{array}$ & $\begin{array}{c}\varphi^{*} \\
\text { (degrees) }\end{array}$ & $\beta_{\mathrm{HL}}$ & $F_{c}$ & $F_{\varphi}$ \\
\hline \multicolumn{11}{|c|}{ (a) Normal variables } \\
\hline 34.5 & 7.00 & 17.00 & 0.000 & 1.00 & 1.00 & 7.00 & 17.00 & 0.000 & 1.00 & 1.00 \\
\hline 40 & 6.44 & 15.94 & 0.740 & 1.09 & 1.07 & 6.71 & 15.68 & 1.032 & 1.04 & 1.09 \\
\hline 50 & 5.71 & 14.36 & 1.816 & 1.23 & 1.19 & 6.69 & 13.62 & 2.433 & 1.05 & 1.26 \\
\hline 60 & 5.23 & 12.89 & 2.736 & 1.34 & 1.34 & 6.92 & 11.82 & 3.550 & 1.01 & 1.46 \\
\hline 70 & 4.89 & 11.63 & 3.502 & 1.43 & 1.49 & 7.16 & 10.32 & 4.478 & 0.98 & 1.68 \\
\hline 80 & 4.67 & 10.46 & 4.199 & 1.50 & 1.66 & 7.58 & 8.95 & 5.242 & 0.92 & 1.94 \\
\hline \multicolumn{11}{|c|}{ (b) Nonnormal variables } \\
\hline 34.8 & 7.00 & 17.00 & 0.000 & 1.00 & 1.00 & 7.00 & 17.00 & 0.000 & 1.00 & 1.00 \\
\hline 40 & 6.40 & 15.97 & 0.691 & 1.09 & 1.07 & 6.65 & 15.77 & 0.934 & 1.05 & 1.08 \\
\hline 50 & 5.82 & 14.25 & 1.847 & 1.20 & 1.20 & 6.59 & 13.70 & 2.438 & 1.06 & 1.25 \\
\hline 60 & 5.42 & 12.79 & 2.858 & 1.29 & 1.35 & 6.59 & 12.03 & 3.714 & 1.06 & 1.43 \\
\hline 70 & 5.17 & 11.46 & 3.784 & 1.35 & 1.51 & 7.03 & 10.68 & 4.718 & 1.00 & 1.62 \\
\hline 80 & 4.92 & 10.35 & 4.626 & 1.42 & 1.67 & 7.51 & 9.47 & 5.613 & 0.93 & 1.83 \\
\hline
\end{tabular}




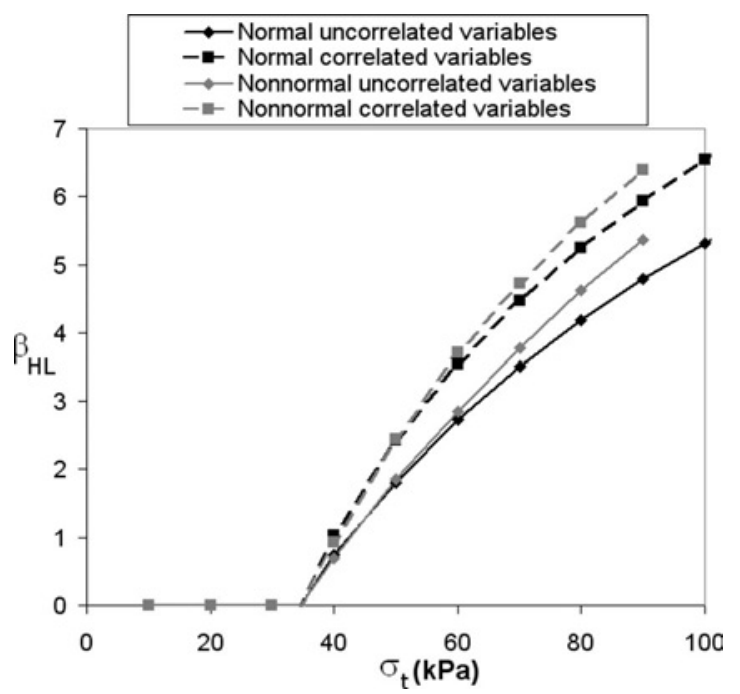

Fig. 10. HL versus applied pressure

correlation may be explained with the aid of Fig. 11 in which the critical ellipse corresponding to a negative correlation is greater than that of no correlation. The reliability index of nonnormal variables is slightly greater than that of normal variables. For the same pressure of $60 \mathrm{kPa}$, the reliability index increases by only $5 \%$ if the variables are considered as nonnormal. The observation that both normal and nonnormal variables give close results may be explained by the fact that the cumulative distribution functions of normal and nonnormal variables are practically similar in the zone of interest to the engineers corresponding to the different design points obtained in the paper these curves are not shown in the paper.

The values of the design points corresponding to different values of the applied pressure can give an idea about the partial safety factors of each of the strength parameters $\psi$ and tan as follows:

$$
\begin{gathered}
\Phi_{\psi}=\frac{\psi}{\psi} \\
\Phi=\frac{\tan \in}{\tan }
\end{gathered}
$$

Table 2 shows that for uncorrelated shear strength parameters, the values of $\psi$ and at the design point are smaller than their respective mean values and decrease with the increase in the ap-

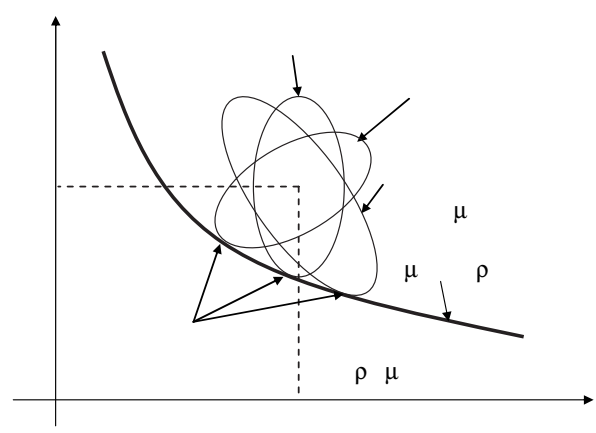

Fig. 11. General layout of the critical dispersion ellipse for different values of the correlation coefficient plied pressure. Consequently, the partial safety factors $\Phi_{\psi}$ and $\Phi$ decrease with the decrease in the applied pressure. They tend to 1 when $=\psi_{\psi}$. For negatively correlated shear strength parameters, $\psi$ slightly exceeds the mean for some values of the applied pressure. This can be explained by the counterclockwise rotation of the critical dispersion ellipse due to the negative correlation cf. Fig. 11. The position of the design point, which is the point of tangency between the critical ellipse and the limit state surface, changes from the one found for uncorrelated soil shear strength parameters. A higher value of $\psi$ and a lower value of were found in the case of negative correlation. Consequently, $\psi$ can become greater than the mean value for a negative correlation. This conclusion is similar to that found by Youssef Abdel Massih and Soubra 2008.

\section{SLS}

The classical RSM used before in the ULS was found not convenient in the present case of the SLS. Two issues were encountered:

1. It was impossible to compute a settlement for some sampling points after a given number of iterations. This is because these cases lead to a collapse of the tunnel face. This occurred when calculating the settlement corresponding to points such as $\oplus-\psi, \quad, \quad$ or $\oplus, \quad-\quad, \quad$ for which a smaller value of $\psi$ or was considered for the settlement computations.

2. It was found that the successive iterations of the RSM do not converge to a design point when using a quadratic approximation for the limit state surface. Another form of this limit state function was necessary as will be seen later.

The first issue may be explained with the aid of Fig. 12a. This figure shows the seven sampling points projected on a $\$$, plane. Thus, only five points are visible in that figure. It can be easily seen that some sampling points can lead to a collapse of the tunnel face since they correspond to shear strength parameters located in the failure zone of the $\notin$, plane as defined in the ULS study. Two different ways may be used to overcome this issue. The first one consists in reducing the value defined in the RSM, as shown in Fig. 12b. This resolves the collapse issue for all the sampling points but unfortunately it does not lead to convergence. This is because the approximation of the limit state surface was not accurate in this case; this surface being based on very neighboring sampling points. A second and more efficient method is proposed in Fig. 12c where the shear strength parameters are chosen in a nonsymmetrical manner with respect to the central point. Thus, the seven sampling points used for the determination of the limit state surface approximation become $\notin, \quad, \quad+1.2_{\psi}, \quad, \quad \$-0.3_{\psi}, \quad, \quad, \quad+1.4$, $\oplus,-0.3, \quad$, $\$,, \quad+$, and $\oplus,, \quad-\quad$. This choice of the sampling points was made arbitrarily. It prevents the face collapse by not reducing too much the value of $\psi$ and. It slightly shifts the sampling points to the safe domain. However, these points remain close to the limit state surface in order to obtain a good approximation of this surface. Notice finally that the choice of the values of has a small influence on the results. The sampling points can thus be located anywhere in the neighborhood of the design point. This method will be used in all subsequent SLS simulations.

The second issue is due to the use of a quadratic approximation for the limit state surface. In the present case of the SLS, this approximation was found not convenient since it does not make 

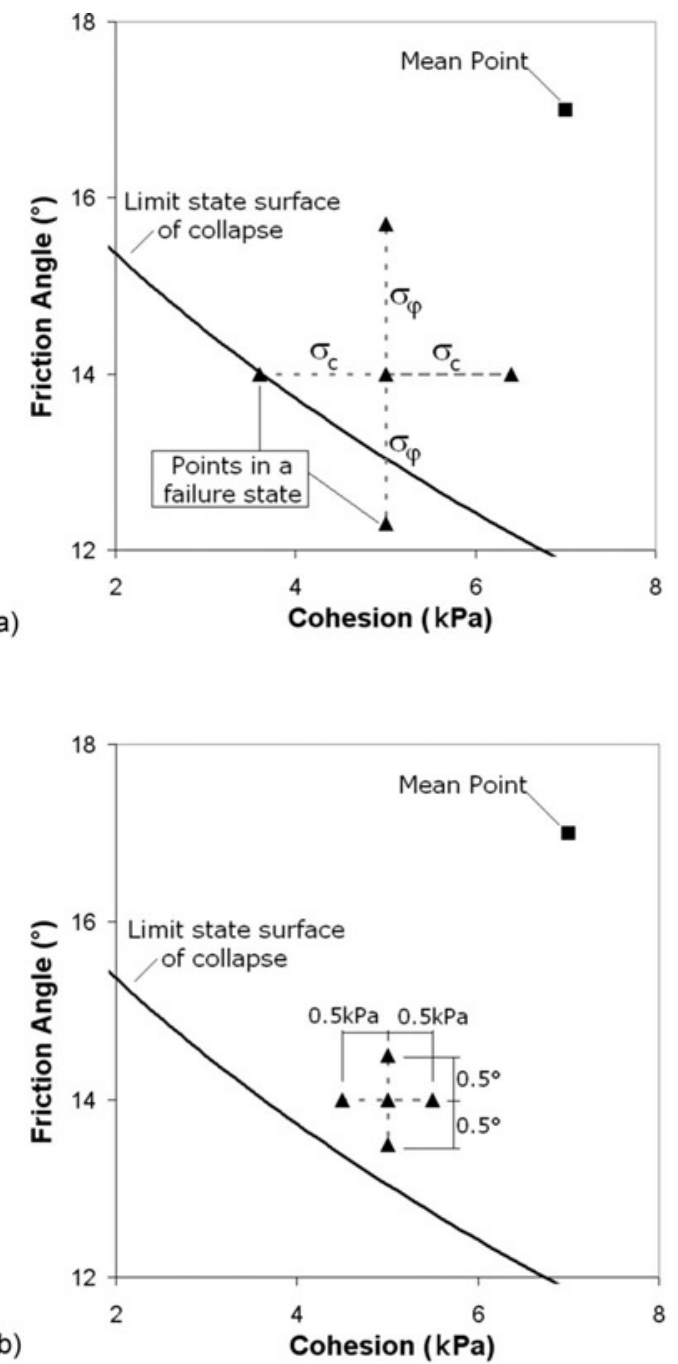

(b)

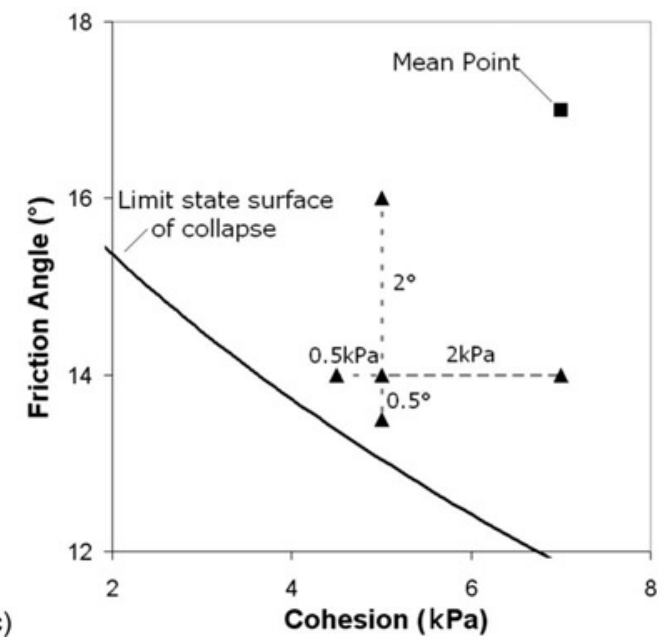

Fig. 12. Different patterns used in SLS (projected on a $(c, \varphi)$ plane): (a) classic pattern; (b) improved pattern with a reduced $k$ value; and (c) adopted nonsymmetrical pattern

the RSM iterations converge to the design point. A study of a significant number of FLAC ${ }^{3 \mathrm{D}}$ simulations for several values of $c$, $\varphi$, and $E$ has shown that the settlement increases with the decrease in $c, \varphi$, and $E$. The numerical simulations have also shown that an infinite settlement corresponding to the collapse of the tunnel face is obtained when one uses the $(c, \varphi)$ points of the limit state surface of the ULS. From the ULS study, it can be shown that the critical limit state function defined by Eq. (4) (i.e., $G_{1}$ $=0$ ) can be approximated by the following function:

$$
\varphi=\alpha_{1} c^{2}+\alpha_{2} c+\alpha_{3}
$$

where $\alpha_{1}, \alpha_{2}$, and $\alpha_{3}$ are constants. By taking into account the aforementioned observations concerning the sensitivity of the maximal settlement to the different input parameters (i.e., $c, \varphi$, and $E$ ), the following equation is suggested as an approximation for the maximal settlement:

$$
v(c, \varphi, E) \approx a_{1}+\frac{a_{2}}{\varphi-\left(a_{3} c^{2}+a_{4} c+a_{5}\right)}+a_{6} E+a_{7} E^{2}
$$

The values of $a_{3}, a_{4}$, and $a_{5}$ are not equal to the values of $\alpha_{1}, \alpha_{2}$, and $\alpha_{3}$ but remain very close. As can be seen from this equation, the maximal settlement increases with the decrease in $c, \varphi$, and $E$ and is equal to infinity for the $(c, \varphi)$ points of the limit state surface in ULS. Eq. (10) is governed by seven constants $a_{i}(i$ $=1-7$ ) and needs seven FLAC ${ }^{3 \mathrm{D}}$ settlement computations to be defined. The nonsymmetrical pattern presented in Fig. 12(c) is used. As the present limit state surface is close to the real one, the convergence to the design point was ensured within three or four RSM iterations. This allows one to get the reliability index with ease for a given applied pressure and for a given prescribed settlement. The corresponding $\mathrm{CPU}$ time required is about 28 $\times 130 \mathrm{~min}=3,640 \mathrm{~min}$ (i.e., $60 \mathrm{~h}$ ). As an example, the values of the seven constants corresponding to the best approximation of the limit state surface and the corresponding reliability results are given in Table 3 for the case of normal uncorrelated variables and for an applied pressure $\sigma_{t}=70 \mathrm{kPa}$ when $v_{\max }=5 \mathrm{~mm}$. This table gives also the tentative reliability index and design point at the different iterations. Notice that the maximal settlement at the design point as computed by FLAC $^{3 \mathrm{D}}$ is equal to $5.01 \mathrm{~mm}$. This settlement is to be compared to the target settlement of $5 \mathrm{~mm}$. Thus, as in the ULS, one can consider the RSM algorithm used in this paper as sufficiently accurate for the computation of the reliability index.

Fig. 13 shows the unit and critical dispersion ellipsoids and the limit state surface for an applied pressure equal to $60 \mathrm{kPa}$ and a prescribed settlement equal to $5 \mathrm{~mm}$ in the case of normal uncorrelated variables. The critical dispersion ellipsoid is the smallest one that just touches the limit state surface.

\section{Reliability Index and Design Point}

Fig. 14 presents the reliability index of the SLS versus the applied pressure $\sigma_{t}$ for three different cases:

1. Normal variables with a maximal prescribed settlement equal to $5 \mathrm{~mm}$;

2. Nonnormal variables with a maximal prescribed settlement equal to $5 \mathrm{~mm}$; and

3. Normal variables with a maximal prescribed settlement equal to $10 \mathrm{~mm}$.

In all these cases, no correlation was considered between the three random variables. The values of the design point and the partial safety factors $\left(F_{c}, F_{\varphi}\right.$, and $\left.F_{E}\right)$ are given in Table 4 . The same interpretation of the ULS results in terms of the design point and safety factors remain valid in the present case of SLS and thus will not be repeated herein. Fig. 14 shows that (i) the assumption of nonnormal variables has almost no effect on the re- 
Table 3. Design Point along the Different RSM Iterations for SLS $\left(\sigma_{t}=70 \mathrm{kPa}\right.$ and $\left.v_{\max }=5 \mathrm{~mm}\right)$

\begin{tabular}{lcccc}
\hline RSM iteration number $(i)$ & Mean point & 1 & 2 & 3 \\
\hline$B_{\mathrm{HLi}}$ & 0 & 3.685 & 2.909 & 2.897 \\
$c_{i}(\mathrm{kPa})$ & 7 & 5.22 & 5.41 & 5.58 \\
$\varphi_{i}(\mathrm{deg})$ & 17 & 11.28 & 12.65 & 2.903 \\
$E_{i}(\mathrm{MPa})$ & 240 & 211.05 & 211.25 & 12.58 \\
& Best approximation of the limit state surface at the fourth iteration: & 220.94 \\
& $a_{1}=11.67 ; a_{2}=5.20 ; a_{3}=0.0357 ; a_{4}=-0.882 ; a_{5}=14.75 ; a_{6}=-0.0684 ;$ and $a_{7}=0.000103$ \\
\hline
\end{tabular}

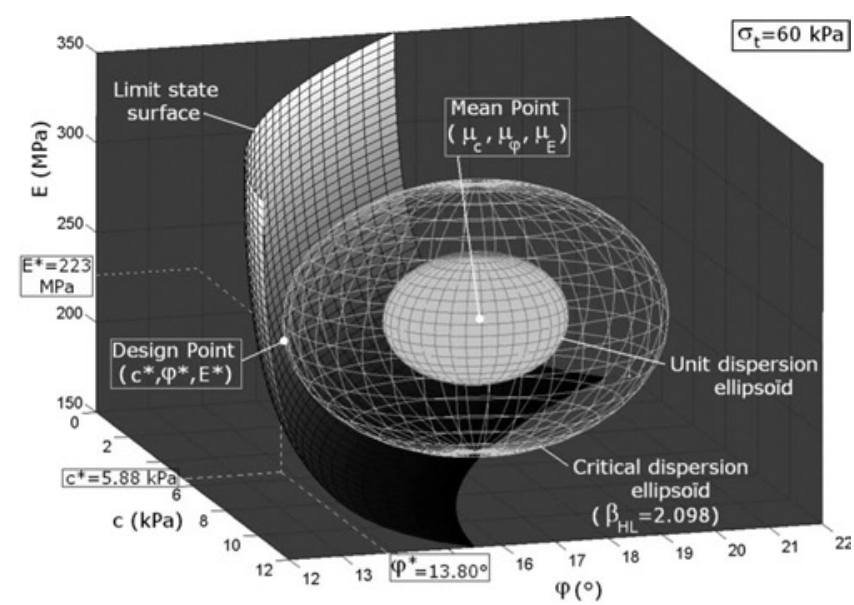

(a)

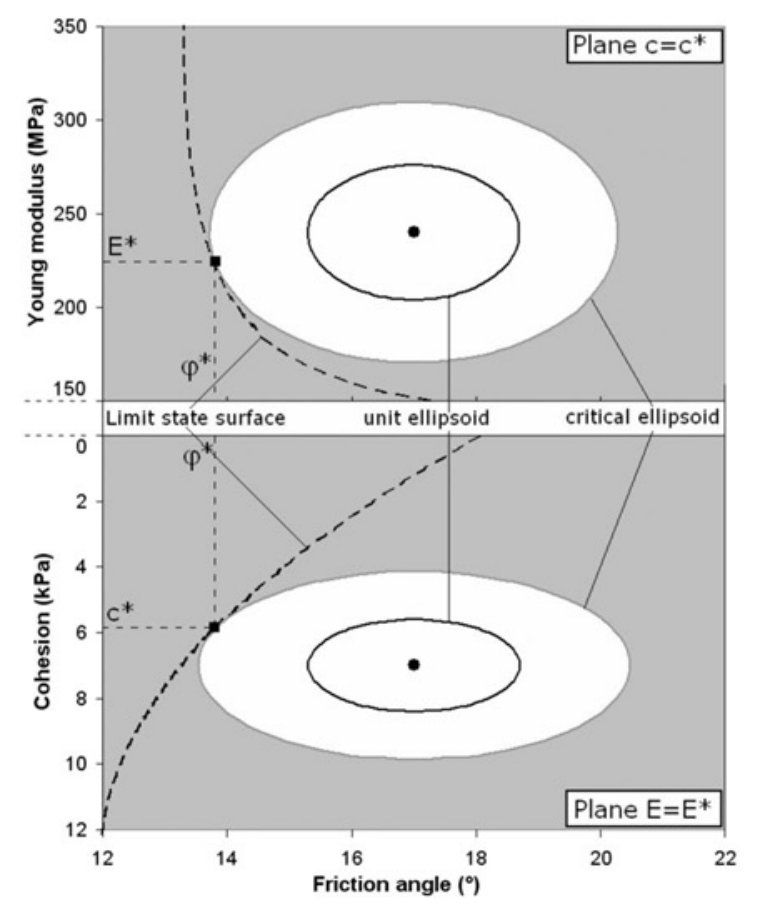

(b)

Fig. 13. Graphical representation of unit and critical dispersion ellipsoids for SLS: (a) in the three-dimensional space; (b) projected on the planes $c=c^{*}$ and $E=E^{*}$ liability index for $\sigma_{t}<60 \mathrm{kPa}$ as in the ULS case and (ii) a prescribed settlement of $10 \mathrm{~mm}$ instead of $5 \mathrm{~mm}$ increases the reliability index; the increase is equal to $16 \%$ when $\sigma_{t}=70 \mathrm{kPa}$.

\section{Comparison between the Two Limit States}

Fig. 15 shows a comparison between the values of $\beta_{\mathrm{HL}}$ given by the ULS and the SLS (in both cases of $\nu_{\max }=5 \mathrm{~mm}$ and $\nu_{\max }$ $=10 \mathrm{~mm}$ ). The reliability index of both limit states have almost the same evolution versus the applied pressure. This may be explained by the fact that both limit states are controlled by the same parameters (mainly $c$ and $\varphi$ ) and correspond to the same physical phenomenon: the occurrence of a settlement can be considered as the beginning of a failure state because it implies plastic deformations around the tunnel face. Finally, from Fig. 15, one can easily see that the reliability index against face collapse and the one against a 10-mm maximal settlement are almost the same.

Table 5 gives the components and the system reliability index of both limit states. The equations used are given in Youssef Abdel Massih and Soubra (2008) and are not repeated herein. The coefficient of correlation between the two limit states was found very close to $1\left(0.97<\rho_{\text {ULS-SLS }}<1\right)$ for the different applied pressures. This indicates a strong positive correlation between both limit states and confirms the observation made above concerning the evolution of both limit states in the same manner. It was also found that the system reliability index depends on both limit states. It is smaller than the reliability index corresponding to a single failure mode but it is very close to the one of SLS. It is equal to that of SLS for high values of the applied pressure.

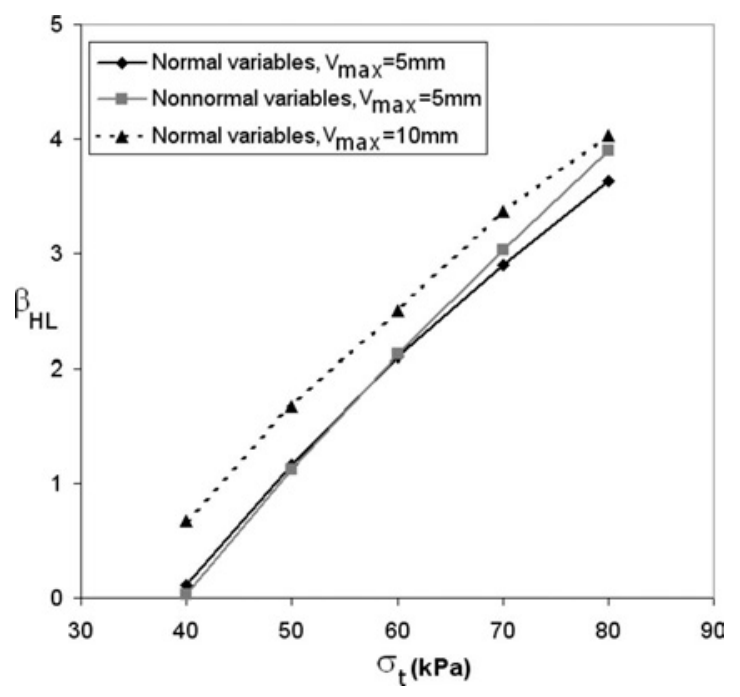

Fig. 14. Reliability index versus applied pressure $\sigma_{t}$ for SLS 
Table 4. Reliability Index and Design Point for SLS for Normal and Nonnormal Variables with No Correlation

\begin{tabular}{|c|c|c|c|c|c|c|c|}
\hline $\begin{array}{l}\sigma_{t} \\
(\mathrm{kPa})\end{array}$ & $\begin{array}{c}c^{*} \\
(\mathrm{kPa})\end{array}$ & $\begin{array}{c}\varphi^{*} \\
(\mathrm{deg})\end{array}$ & $\begin{array}{c}E^{*} \\
(\mathrm{MPa})\end{array}$ & $\beta_{\mathrm{HL}}$ & $F_{c}$ & $F_{\varphi}$ & $F_{E}$ \\
\hline \multicolumn{8}{|c|}{ (a) Normal variables, maximal settlement equal to $5 \mathrm{~mm}$} \\
\hline 40 & 6.90 & 16.87 & 239.25 & 0.109 & 1.01 & 1.01 & 1.00 \\
\hline 50 & 6.32 & 15.26 & 230.16 & 1.165 & 1.11 & 1.12 & 1.04 \\
\hline 60 & 5.88 & 13.80 & 222.95 & 2.098 & 1.19 & 1.24 & 1.08 \\
\hline 70 & 5.51 & 12.50 & 220.94 & 2.903 & 1.27 & 1.38 & 1.10 \\
\hline 80 & 5.16 & 11.39 & 213.53 & 3.628 & 1.36 & 1.52 & 1.12 \\
\hline \multicolumn{8}{|c|}{ (b) Nonnormal variables, maximal settlement equal to $5 \mathrm{~mm}$} \\
\hline 40 & 6.85 & 16.92 & 237.07 & 0.030 & 1.02 & 1.01 & 1.01 \\
\hline 50 & 6.29 & 15.31 & 227.79 & 1.121 & 1.11 & 1.12 & 1.05 \\
\hline 60 & 5.93 & 13.82 & 220.22 & 2.121 & 1.18 & 1.24 & 1.09 \\
\hline 70 & 5.62 & 12.53 & 213.40 & 3.035 & 1.25 & 1.38 & 1.12 \\
\hline 80 & 5.38 & 11.33 & 208.99 & 3.899 & 1.30 & 1.53 & 1.15 \\
\hline \multicolumn{8}{|c|}{ (c) Normal variables, maximal settlement equal to $10 \mathrm{~mm}$} \\
\hline 40 & 6.54 & 16.00 & 239.20 & 0.673 & 1.07 & 1.07 & 1.00 \\
\hline 50 & 5.99 & 14.43 & 238.29 & 1.676 & 1.17 & 1.19 & 1.01 \\
\hline 60 & 5.52 & 13.00 & 237.76 & 2.500 & 1.27 & 1.32 & 1.01 \\
\hline 70 & 5.09 & 11.77 & 235.32 & 3.367 & 1.38 & 1.47 & 1.02 \\
\hline 80 & 4.83 & 10.76 & 233.00 & 4.031 & 1.45 & 1.61 & 1.03 \\
\hline
\end{tabular}

Hence, the contribution of ULS to the system reliability is not significant. As a conclusion, SLS can be used alone for the assessment of the tunnel reliability.

\section{Conclusions}

A reliability-based analysis of a shallow circular tunnel driven by a pressurized shield in a $c-\varphi$ soil is presented. Both the ULS and the SLS are considered in the analysis. Two deterministic models based on numerical simulations using the Lagrangian explicit finite-difference code FLAC ${ }^{3 \mathrm{D}}$ are employed. The first one computes the collapse pressure of the tunnel face and the second one calculates the maximal settlement due to a given applied pressure on the tunnel face. In both models, the stress control method is

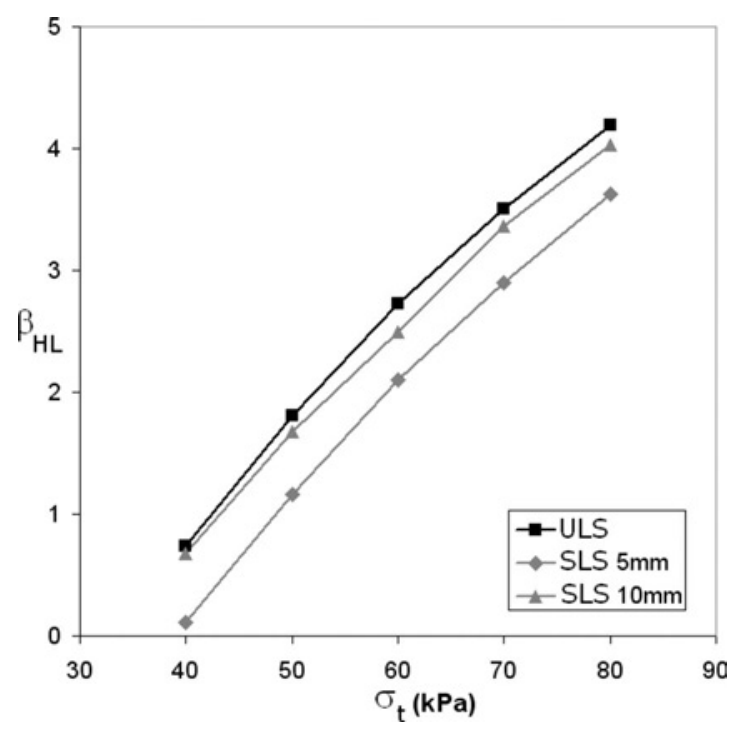

Fig. 15. Comparison between ULS and SLS used. Concerning the assessment of the tunnel reliability, the Hasofer-Lind reliability index is adopted here. The RSM is used to find an approximation of the analytically unknown limit state surfaces and the corresponding reliability indices. Only the soil shear strength parameters are considered as random variables while studying the ULS. However, the randomness of both Young's modulus and the shear strength parameters of the soil is taken into account in the SLS. The main conclusions of this paper can be summarized as follows.

For the ULS, the hypothesis of uncorrelated shear strength parameters was found conservative in comparison to the one of negatively correlated variables. For uncorrelated shear strength parameters, the values of $c^{*}$ and $\varphi^{*}$ at the design point are found smaller than their respective mean values and increase with the decrease in the applied pressure $\sigma_{t}$. Consequently, the partial safety factors $F_{c}$ and $F_{\varphi}$ decrease with the decrease in the applied pressure. They tend to 1 when $\sigma_{t}=\sigma_{c}$. For negatively correlated shear strength parameters, $c^{*}$ slightly exceeds the mean for some values of the applied pressure.

For the SLS, when the shear strength parameters are considered as uncorrelated, the partial safety factors $F_{c}, F_{\varphi}$, and $F_{E}$ decrease with the decrease in $\sigma_{t}$. They tend to 1 when $\sigma_{t}$ is equal to the pressure that leads to the maximal prescribed settlement $v_{\max }$ for the mean values of $c, \varphi$, and $E$.

For both ULS and SLS, the assumption of nonnormal distri-

Table 5. Reliability Index of the System ULS-SLS for $v_{\max }=5 \mathrm{~mm}$

\begin{tabular}{lccc}
\hline & \multicolumn{3}{c}{$\beta_{\mathrm{HL}}$} \\
\cline { 2 - 4 } $\begin{array}{l}\sigma_{t} \\
\mathrm{kPa})\end{array}$ & ULS & SLS & $\begin{array}{c}\text { System } \\
\text { ULS-SLS }\end{array}$ \\
\hline 40 & 0.740 & 0.109 & 0.089 \\
50 & 1.806 & 1.165 & 1.163 \\
60 & 2.726 & 2.098 & 2.097 \\
70 & 3.502 & 2.901 & 2.901 \\
80 & 4.189 & 3.628 & 3.628 \\
\hline
\end{tabular}


bution for the random variables has almost no effect on the reliability index for the practical range of values of the applied pressure $\sigma_{t}$. The reliability index of both limit states follows the same evolution with the increase in the applied pressure. This may be explained by the fact that both limit states are controlled by the same parameters (mainly $c$ and $\varphi$ ) and correspond to the same physical phenomenon: the occurrence of a settlement can be considered as the beginning of a failure state because it implies plastic deformations around the tunnel face.

It was found that the system reliability index depends on both limit states. It is smaller than the reliability index corresponding to a single failure mode but it is very close to the one of SLS. It is equal to that of SLS for high values of the applied pressure. Hence, the contribution of ULS to the system reliability is not significant. As a conclusion, SLS can be used alone for the assessment of the tunnel reliability. It should be remembered here that SLS in the present paper is based on the computation of the settlement due to only the face pressure. In a future work, it is suggested to investigate a more sophisticated SLS deterministic model that considers an exhaustive analysis of the total settlement due to the different construction parameters and to perform a probabilistic analysis based on this unique limit state. The new probabilistic SLS model can take advantage of the thorough analysis concerning (1) the shape of the response surface found in the paper; and (2) the nonsymmetrical pattern of the sampling points since the influence of both $c$ and $\varphi$ on the settlement is expected to remain the same in the new sophisticated deterministic model.

\section{References}

Baecher, G. B., and Christian, J. T. (2003). Reliability and statistics in geotechnical engineering, Wiley.

Bauer, J., and Pula, W. (2000). "Reliability with respect to settlement limit-states of shallow foundations on linearly-deformable subsoil." Comput. Geotech., 26(1), 281-308.

Cherubini, C., Giasi, I., and Rethati, L. (1993). "The coefficient of variation of some geotechnical parameters." Probabilistic methods in geotechnical engineering, K. S. Li and S.-C. R. Lo, eds., Balkema, Rotterdam, 179-183.

Dias, D., and Kastner, R. (2005). "Modélisation numérique de l'apport du renforcement par boulonnage du front de taille des tunnels." Can. Geotech. J., 42, 1656-1674 (in French).

Dias, D., Kastner, R., and Dubois, P. (1997). "Tunnel face reinforcement by bolting: Strain approach using 3D analysis." Proc., Int. Conf. on Tunneling under Difficult Conditions, Basel, Switzerland, Balkema, Rotterdam.

Dias, D., Kastner, R., and Jassionnesse, C. (2002). "Sols renforcés par boulonnage. Etude numérique et application au front de taille d'un tunnel profond." Geotechnique, 52(1), 15-27 (in French).

Ditlevsen, O. (1981). Uncertainty modeling: With applications to multidimensional civil engineering systems, McGraw-Hill, New York.

Eclaircy-Caudron, S., Dias, D., and Kastner, R. (2007). "Inverse analysis on measurements realized during a tunnel excavation." Proc., ITAAITES World Tunnel Congress 2007, Prague, Czech Republic, Barták et al., eds.
Fenton, G. A., and Griffiths, D. V. (2003). "Bearing capacity prediction of spatially random $C-\varphi$ soils." Can. Geotech. J., 40, 54-65.

FLAC $^{3 \mathrm{D}}$. (1993). Fast Lagrangian analysis of continua, ITASCA Consulting Group, Inc., Minneapolis.

Haldar, A., and Mahadevan, S. (2000). Probability, reliability, and statistical methods in engineering design, Wiley, New York.

Hasofer, A. M., and Lind, N. C. (1974). "Exact and invariant secondmoment code format." J. Engrg. Mech. Div., 100(1), 111-121.

Jardine, R. J., Potts, D. M., Fourie, A. B., and Burland, J. B. (1986). "Studies of the influence of nonlinear stress strain characteristics in soil-structure interaction." Geotechnique, 36(3), 377-396.

Jenck, O., and Dias, D. (2003). "Numerical analysis of the volume loss influence on building during tunnel excavation." Proc., 3rd Int. FLAC Symp._FLAC and FLAC3D Numerical Modeling in Geomechanics, Sudbury, Ontario, Canada, C. Detournay and R. Hart, eds.

Jenck, O., and Dias, D. (2004). “Analyse tridimensionnelle en différences finies de l'interaction entre une structure en béton et le creusement d'un tunnel à faible profondeur." Geotechnique, 54(8), 519-528 (in French).

Low, B. K. (2005). "Reliability-based design applied to retaining walls." Geotechnique, 55(1), 63-75.

Low, B. K., and Tang, W. H. (1997a). "Efficient reliability evaluation using spreadsheet." J. Eng. Mech., 123(7), 749-752.

Low, B. K., and Tang, W. H. (1997b). "Reliability analysis of reinforced embankments on soft ground." Can. Geotech. J., 34, 672-685.

Low, B. K., and Tang, W. H. (2004). "Reliability analysis using objectoriented constrained optimization." Struct. Safety, 26, 69-89.

Mollon, G., Dias, D., and Soubra, A.-H. (2009). "Probabilistic analysis and design of circular tunnels against face stability." Int. J. Geomech., in press.

Mroueh, H., and Shahrour, I. (2003). "A full 3-D finite element analysis of tunneling-adjacent structures interaction." Computers and Geotechnics, 30, 245-253.

Phoon, K.-K., and Kulhawy, F. H. (1999). "Evaluation of geotechnical property variablity." Can. Geotech. J., 36, 625-639.

Potts, D. M., and Addenbrooke, T. I. (1997). "A structure's influence on tunneling induced ground movements." Geotech. Eng., 125(2), 109125.

Ribeiro e Sousa, L., Dias, D., and Barreto, J. (2003). "Lisbon metro yellow line extension. Structural behavior of the Ameixoeira station." Proc., 12th Panamerican Conf. on Soil Mechanics and Geotechnical Engineering, Boston, Verlag Glückauf Gmbh, eds.

Tandjiria, V., Teh, C. I., and Low, B. K. (2000). "Reliability analysis of laterally loaded piles using response surface methods." Struct. Safety, 22, 335-355.

Vanoudheusden, E. (2006). "Impact de la construction de tunnels urbains sur les mouvements de sol et le bâti existant-Incidence du mode de pressurisation du front.” Ph.D. thesis, INSA Lyon, Lyon, France (in French).

Wong, H., Subrin, D., and Dias, D. (2006). "Convergence-confinement analysis of a bolt-supported tunnel using homogenization method." Can. Geotech. J., 43(5), 462-483.

Yoo, C. S. (2002). "Finite-element analysis of tunnel face reinforced by longitudinal pipes." Computers and Geotechnics, 29(1), 73-94.

Youssef Abdel Massih, D. S., and Soubra, A.-H. (2008). "Reliabilitybased analysis of strip footings using response surface methodology." Int. J. Geomech., 8(2), 134-143.

Youssef Abdel Massih, D. S., Soubra, A.-H., and Low, B. K. (2008). "Reliability-based analysis and design of strip footings against bearing capacity failure." J. Geotech. Geoenviron. Eng., 134(7), 917-928. 